\title{
Serum Carcinoembryonic Antigen as a Biomarker for Medullary Thyroid Cancer
}

\author{
Jinyoung Kim ${ }^{1}$, Hyunju Park ${ }^{1}$, Min Sun Choi ${ }^{1}$, Jun Park ${ }^{1}$, Hye Won Jang ${ }^{2}$, \\ Tae Hyuk Kim ${ }^{1}$, Sun Wook Kim ${ }^{1}$ and Jae Hoon Chung ${ }^{1}$
}

Division of Endocrinology \& Metabolism, Department of Medicine, Thyroid Center, Samsung Medical Center, Sungkyunkwan University School of Medicine ${ }^{1}$, Department of Medical Education, Sungkyunkwan University School of Medicine ${ }^{2}$, Seoul, Korea

Background and Objectives: The lack of known elevated biomarkers in cancer surveillance is a challenge for diagnostics. However, few studies have assessed the proportion of patients with medullary thyroid cancer (MTC) that presented with elevated serum carcinoembryonic antigen (CEA) level. Materials and Methods: This was a retrospective study of 115 patients treated for MTC at Samsung Medical Center between 1995 and 2017. Serum calcitonin and CEA levels that were available at one of the following time points were included: (a) within 3 months before the initial surgery, (b) when a structural recurrence was confined to the neck, or (c) when a distant metastasis was identified during follow-up. Considering the high false-positive rate of serum CEA testing, $5 \mathrm{ng} / \mathrm{mL}$ was selected as the cut-off threshold. Results: The sensitivity of CEA at the time of diagnosis was 54\%, but it significantly increased with anatomical stage, from $20 \%$ in stage I to $88 \%$ in stage IV ( $p$ for trend $<0.001$ ). At the time of diagnosis, larger tumor size, more frequent gross extra-thyroidal extension, more frequent N1b, and a higher number of metastatic lymph nodes were significantly observed in CEA-positive patients compared with CEA-negative patients $(p<0.05)$. The sensitivity of CEA at the time of recurrence was $56 \%$ for local recurrence and $80 \%$ for distant recurrence. Conclusion: The CEA value was associated with anatomical stage as a biomarker for MTC and could be used to predict poor prognosis. However, serum CEA testing plays a limited role in diagnosis and follow-up of MTC because it can show normal values even in advanced disease.

Key Words: Thyroid neoplasms, Biomarkers, Carcinoembryonic antigen

\section{Introduction}

Medullary thyroid cancer (MTC) is a neuroendocrine tumor characterized by proliferation of para-follicular cells in the thyroid gland and was recognized and reported as a distinct tumor in 1959.") Although it is a relatively rare disease with a prevalence of less than $5 \%$ among thyroid cancers, it has attracted research attention due to its characteristic clinical features and aggressiveness compared to differentiated thyroid cancers. ${ }^{2)}$
Para-follicular cells are classified as C-cells because they produce calcitonin, ${ }^{3)}$ which is a useful biomarker in MTC. Similar to other neuroendocrine tumors, MTC can produce other biochemical markers such as catecholamine, neuron-specific enolase, and chromogranin A. ${ }^{4)}$ Among them, carcinoembryonic antigen (CEA) is an established biomarker for MTC. ${ }^{5}$ Current guidelines recommend measuring serum calcitonin and CEA together to evaluate MTC, and the serum levels of these markers directly correlate with the para-follicular or C-cell mass. The presence of serum calcitonin and CEA facilitate predictions for the

Received August 5, 2021 / Revised October 12, 2021 / Accepted October 24, 2021

Correspondence: Jae Hoon Chung, MD, PhD, Division of Endocrinology \& Metabolism, Department of Medicine, Thyroid Center, Samsung Medical Center, Sungkyunkwan University School of Medicine, 81 Irwon-ro, Gangnam-gu, Seoul 06351, Korea Tel: 82-2-3410-3434, Fax: 82-2-6918-4653, E-mail: thyroid@skku.edu 
likelihood of diagnosis or recurrence of MTC. ${ }^{6)}$ Consequently, the levels of these biomarkers and their doubling times are useful for predicting the risk of recurrence after surgical treatment and for evaluating the aggressiveness of metastatic disease. ${ }^{7,8)}$

The lack of known elevated biomarkers in cancer surveillance is challenging for diagnostics. However, few studies have evaluated the proportion of patients with MTC that presented with elevated CEA level. Therefore, this study was conducted to determine the level of serum CEA compared with that of serum calcitonin for diagnosing and predicting recurrence in MTC patients and to identify limitations of serum CEA testing as a biomarker for MTC.

\section{Materials and Methods}

\section{Patients}

We retrospectively reviewed the medical records of patients treated for MTC at Samsung Medical Center between 1995 and 2017. Patients who underwent surgery for curative purposes were enrolled, and the initial anatomical stages of the patients were all below IVA. Patients with serum calcitonin and CEA values that were available at one of the following moments were eligible: (a) within 3 months before the initial surgery $(n=94)$, (b) when structural recurrence was confined to the neck lymph nodes $(n=25)$, or (c) when a distant metastasis was identified during follow-up $(n=20)$. A total of 115 patients was enrolled, including those with a positive biomarker at the various time points. This study was approved by the Institutional Review Board of Samsung Medical Center (SMC 2020-07-134).

\section{Measurements and Definitions}

Serum calcitonin concentration was measured by an immunoradiometric assay using a commercialized assay kit (CT-U.S.-IRMA, DIAsource ImmunoAssays S.A., Louvain-la-Neuve, Belgium). Serum CEA concentration was measured by a radiometric assay using a commercialized assay kit (CEA-RAICT, Cisbio Bioassays, Codolet, France). A serum calcitonin level of $12 \mathrm{pg} / \mathrm{mL}$ or less was defined as normal at the initial MTC diagnosis, ${ }^{9}$ and a level of $5 \mathrm{pg} / \mathrm{mL}$ or less

Table 1. Baseline characteristics of the study population $(n=115)$

\begin{tabular}{|c|c|}
\hline Variable & Value \\
\hline Age, years $($ mean $\pm S D)$ & $50.22 \pm 14.24$ \\
\hline Sex, female $(\%)$ & $72(62.6)$ \\
\hline Size, $\mathrm{cm}($ mean $\pm \mathrm{SD})$ & $1.89 \pm 1.46$ \\
\hline Multifocal tumors, number (\%) & $23(20.0)$ \\
\hline Bilateral tumors, number (\%) & $18(15.7)$ \\
\hline \multicolumn{2}{|l|}{ RET mutation, number (\%) } \\
\hline Positive & $\begin{array}{l}16 / 76 \\
(21.1)\end{array}$ \\
\hline Negative & $\begin{array}{l}60 / 76 \\
(78.9)\end{array}$ \\
\hline \multicolumn{2}{|l|}{$\mathrm{T}$ stage, number $(\%)$} \\
\hline $1 a$ & $40(34.8)$ \\
\hline $1 b$ & $27(23.5)$ \\
\hline 2 & $19(16.5)$ \\
\hline $3 a$ & $7(6.1)$ \\
\hline $3 b$ & $13(11.3)$ \\
\hline $4 a$ & $9(7.8)$ \\
\hline \multicolumn{2}{|l|}{$N$ stage, number $(\%)$} \\
\hline 0 & $47(40.9)$ \\
\hline $1 \mathrm{a}$ & $18(15.6)$ \\
\hline $1 b$ & $50(43.5)$ \\
\hline \multicolumn{2}{|l|}{ AJCC 8th stage, number (\%) } \\
\hline । & $37(32.2)$ \\
\hline$\|$ & $10(8.7)$ \\
\hline III & $18(15.6)$ \\
\hline IVA & $50(43.5)$ \\
\hline \multicolumn{2}{|l|}{ Preoperative serum calcitonin, $\mathrm{pg} / \mathrm{mL}$} \\
\hline Mean & 1,188 \\
\hline Median & 336 \\
\hline Range & $4-17,200$ \\
\hline \multicolumn{2}{|l|}{ Preoperative serum CEA, $\mathrm{ng} / \mathrm{mL}$} \\
\hline Mean & 32.3 \\
\hline Median & 6.4 \\
\hline Range & $0.5-475.7$ \\
\hline \multicolumn{2}{|l|}{ Follow-up duration, years } \\
\hline Median (IQR) & $\begin{array}{c}8.3 \\
(4.9-10.8)\end{array}$ \\
\hline \multicolumn{2}{|l|}{ Clinical outcome, number (\%) } \\
\hline $\begin{array}{l}\text { No evidence of structural recurrence } \\
\text { confirmed by sonography }\end{array}$ & $80(69.6 \%)$ \\
\hline $\begin{array}{l}\text { Local metastasis confined to neck } \\
\text { lymph nodes }\end{array}$ & $15(13.0 \%)$ \\
\hline $\begin{array}{l}\text { Distant metastasis confirmed by } \mathrm{CT} \\
\text { or PET scans }\end{array}$ & $13(11.3 \%)$ \\
\hline Death & $7(6.1 \%)$ \\
\hline
\end{tabular}

AJCC: American Joint Committee on Cancer, CEA: carcinoembryonic antigen, CT: computerized tomography, IQR: interquartile range, MTC: medullary thyroid carcinoma, PET: positron emission tomography, SD: standard deviation 
was considered undetectable after total thyroidectomy based on the functional sensitivity of the test. A serum CEA level of $5 \mathrm{ng} / \mathrm{mL}$ or less was regarded as normal before and after the initial surgery.

Genetic testing was performed by collecting DNA from peripheral blood with consent of the patients or their family members. White blood cells from patients were isolated, and DNA was extracted using a commercial kit (Wizard Genomic DNA Purification kit, Promega, WI, USA) and amplified by polymerase chain reaction using a 9600 thermal cycler (Applied Biosystems, CA, USA). Direct sequencing was performed using the MEN1 gene site (11q13.1) and the MEN2 gene site (10q11.2) ABI Prism 3100 Genetic Analyzer (Applied Biosystems, CA, USA).

Confirmation of MTC was based on the pathologic report after total thyroidectomy, and the size of the primary tumor was measured as the longest diameter of the largest mass. Anatomical staging was based on the 8th edition of the American Joint Committee on Cancer (AJCC) system. In cases of recurrence, local recurrence was diagnosed by sonographic fine-needle aspiration cytology. Distant metastasis was confirmed by chest, abdominal, or pelvis computerized tomog- raphy $(\mathrm{CT})$ scans with contrast or by fluoride-18 fluoro-deoxy-glucose integrated with positron emission tomography/CT (18F-FDG PET/CT).

\section{Statistical Analysis}

Continuous variables are presented as mean \pm standard deviation or median (interquartile range) depending on the type of distribution. Quantitative variables were summarized as count (percentage of the total). To visualize the biomarker levels, the values obtained by logging serum calcitonin and CEA concentrations were box plotted, and linear contrast was used to determine statistical significance. Cochran-Armitage trend tests were used to confirm the correlation between anatomical stage and positive result rates for biomarkers. Continuous variables were assessed using the t-test or Mann-Whitney $U$ test to compare the clinico-pathologic features of CEA-positive and -negative patients, while quantitative variables were analyzed using the Chi-square test or Fisher's exact test. Statistical analysis was performed using $\mathrm{R}$ version 3.6.3 (R Foundation for Statistical Computing, Vienna, Austria).

Table 2. Preoperative serum calcitonin and CEA rates correlated with anatomical stage

\begin{tabular}{|c|c|c|c|c|c|c|c|c|}
\hline \multirow{2}{*}{\multicolumn{2}{|c|}{ Total number }} & \multicolumn{2}{|c|}{ Positive patients } & \multicolumn{2}{|c|}{ Sensitivity (\%) } & \multicolumn{2}{|c|}{$p$ for trend $^{\dagger}$} & \multirow{2}{*}{$\begin{array}{l}\text { Increase in sensitivity } \\
\text { by adding CEA }\end{array}$} \\
\hline & & Calcitonin & CEA & Calcitonin & CEA & Calcitonin & CEA & \\
\hline Stage I & 35 & 31 & 7 & 88.6 & 20.0 & & & $0 \%$ \\
\hline Stage $\|/\| \|$ & 26 & 25 & 15 & 96.2 & 57.7 & & & $0 \%$ \\
\hline Stage IV & 33 & 33 & 29 & 100 & 87.9 & 0.035 & $<0.001$ & $0 \%$ \\
\hline Total patients & 94 & 89 & 51 & 94.7 & 54.3 & & & $0 \%$ \\
\hline
\end{tabular}

${ }^{\dagger} p$-values were calculated using the Cochran-Armitage trend test. CEA: carcinoembryonic antigen

Table 3. Clinical characteristics of calcitonin-negative MTCs at the time of diagnosis

\begin{tabular}{ccccccccccl}
\hline Age & Sex & $\begin{array}{c}\text { RET } \\
\text { mutation }\end{array}$ & $\begin{array}{c}\text { Size } \\
(\mathrm{cm})\end{array}$ & $\begin{array}{c}\mathrm{mLN} \\
(\text { Number })\end{array}$ & $\begin{array}{c}\mathrm{N} \\
\text { stage }\end{array}$ & $\begin{array}{c}\text { AJCC } \\
\text { stage }\end{array}$ & $\begin{array}{c}\text { Ctn } \\
\text { IHC }\end{array}$ & $\begin{array}{c}\text { Ctn } \\
(\mathrm{pg} / \mathrm{mL})\end{array}$ & $\begin{array}{c}\mathrm{CEA} \\
(\mathrm{ng} / \mathrm{mL})\end{array}$ & Clinical outcome \\
\hline 52 & $\mathrm{~F}$ & - & 0.4 & 0 & 0 & $\mid$ & $(+)$ & 11.0 & 1.0 & No evidence of disease \\
60 & $\mathrm{M}$ & - & 0.7 & 0 & 0 & $\mathrm{I}$ & $(+)$ & 9.0 & 3.9 & No evidence of disease \\
50 & $\mathrm{~F}$ & - & 0.5 & 0 & 0 & $\mathrm{I}$ & $(+)$ & 4.0 & 1.4 & No evidence of disease \\
52 & $\mathrm{M}$ & Negative & 0.5 & 5 & $1 \mathrm{a}$ & $\mathrm{III}$ & $(+)$ & 8.5 & 1.3 & No evidence of disease \\
35 & $\mathrm{~F}$ & Positive & 0.3 & 0 & 0 & $\mathrm{I}$ & $(+)$ & 6.8 & 0.5 & No evidence of disease \\
\hline
\end{tabular}

-: uninspected, AJCC: American Joint Committee on Cancer, CEA: carcinoembryonic antigen, Ctn: calcitonin, IHC: immunohistochemistry, $m L N$ : metastatic lymph node 


\section{Results}

\section{Baseline Characteristics}

The mean age of the 115 patients with MTC was 50 years, with a range from 13 to 84 years, and 72 patients (62.6\%) were women. Among 76 patients tested for the RET mutation, 16 (21.1\%) were confirmed to have the mutation. The mean tumor size was $1.9 \mathrm{~cm}$, and the size ranged from 0.2 to $9.0 \mathrm{~cm}$, and 18 patients $(15.7 \%)$ had bilateral tumors. Lymph node metastasis was identified in 68 patients (59.1\%). When the 115 patients were classified using the AJCC (8th edition) staging system, $37(32.2 \%)$ were classed as stage I, $10(8.7 \%)$ as stage II, $18(15.7 \%)$ as stage III, and $50(43.5 \%)$ as stage IVA. The median concentration of preoperative serum calcitonin was 336 $\mathrm{pg} / \mathrm{mL}$, and the value ranged from 4 to $17,200 \mathrm{pg} / \mathrm{mL}$; the median concentration of preoperative serum CEA was $6.4 \mathrm{ng} / \mathrm{mL}$ and ranged from 0.5 to $475.7 \mathrm{ng} / \mathrm{mL}$ (Table 1).

\section{Preoperative Serum Calcitonin \& CEA Levels and Their Association with Tumor Stage}

Preoperative serum calcitonin level was positive ( $>$ $12 \mathrm{pg} / \mathrm{mL}$ ) in most patients (89/94, 94.7\%), but five (5.3\%) had normal serum level at the initial diagnosis (Table 2). The five calcitonin-negative patients had tu-

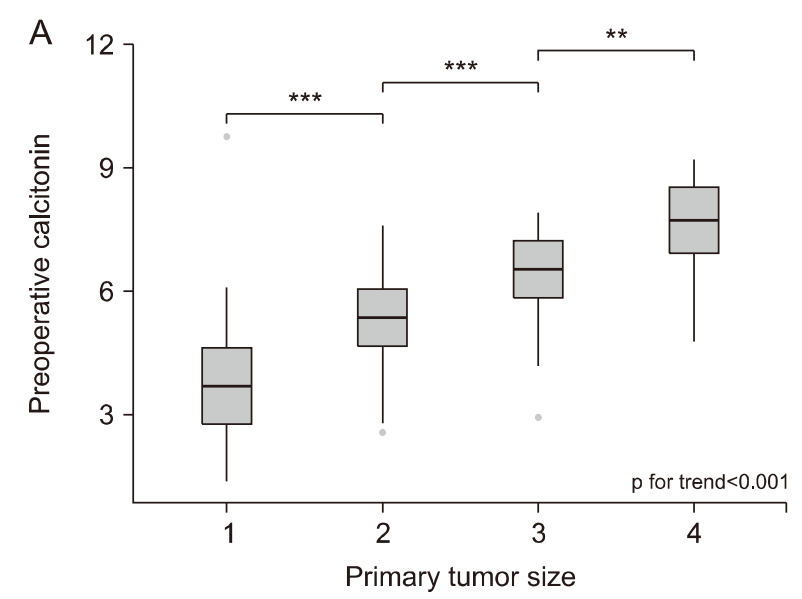

mors that were less than $0.7 \mathrm{~cm}$ in size, and all except one were in stage I. These patients had normal serum CEA level and remained in remission after the initial surgery through the end of the study (Table 3). Preoperative serum CEA level was positive $(>5 \mathrm{ng} / \mathrm{mL})$ in 51 (54.3\%) of 94 patients (Table 2). Preoperative serum calcitonin level was correlated with the serum CEA level $(R=0.78, p<0.001$, Fig. 1). Preoperative serum calcitonin and serum CEA levels increased significantly as tumor size increased ( $p$ for trend $<0.001$, Fig. 2). Positive rates of preoperative serum calcitonin and CEA levels increased significantly with stage $(p=0.035$ and $p<0.001$, respectively; Table 2 ).

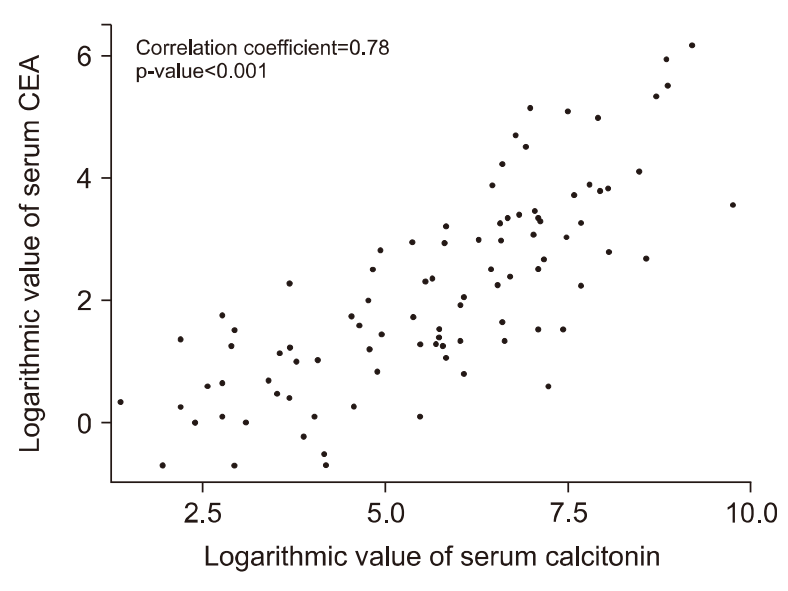

Fig. 1. Correlation between preoperative serum calcitonin and CEA levels.

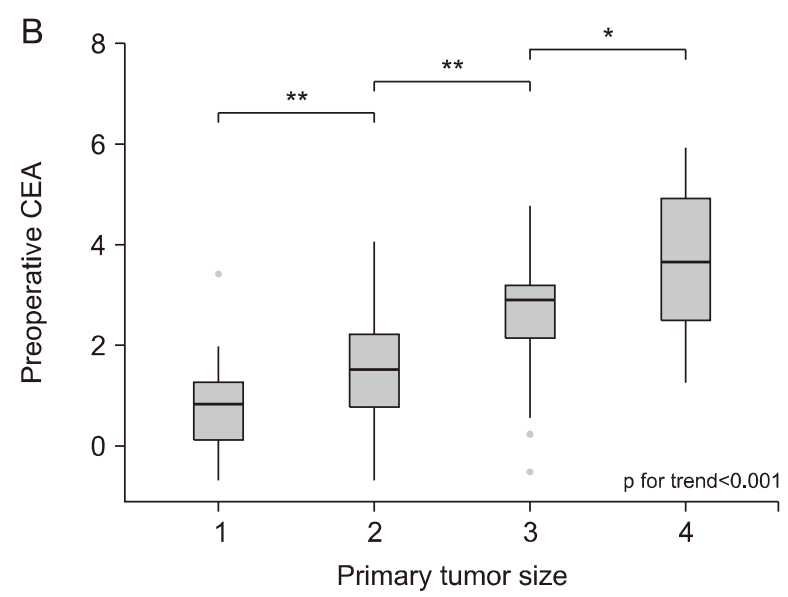

Fig. 2. Preoperative serum calcitonin and CEA levels based on the primary tumor size quantile. (A) Serum calcitonin. (B) Serum CEA. Serum calcitonin and CEA levels are represented as logarithmic values. *Statistically significant with $p \leq 0.05 ;{ }^{*}$ statistically significant with $p \leq 0.01 ;{ }^{* * *}$ statistically significant with $p \leq 0.001$. 


\section{Comparison of the Clinicopathologic Characteristics between Preoperative Serum CEA-Positive and Negative Patients}

When the clinicopathologic characteristics of preoperative serum CEA-positive ( $>5 \mathrm{ng} / \mathrm{mL}$ ) and CEAnegative patients were compared, there were no differences in age, sex, or multifocality between the two groups. However, larger tumor size, more frequent gross extrathyroidal extension, more frequent $\mathrm{N} 1 \mathrm{~b}$, and a higher number of metastatic lymph nodes were significantly observed in the CEA-positive patients compared with the CEA-negative patients $(p<0.05$, Table 4).

\section{Serum Calcitonin \& CEA Levels for Detecting Local or Distant Recurrence}

Serum calcitonin and CEA levels have been used in postoperative surveillance to predict recurrence of MTC. Therefore, the sensitivity of each biomarker was evaluated at the time of detection of local or distant recurrence. The median levels of postoperative serum calcitonin and CEA were $427 \mathrm{pg} / \mathrm{mL}$ and $5.8 \mathrm{ng} / \mathrm{mL}$, respectively, in patients with recurrence confined to the neck and $3200 \mathrm{pg} / \mathrm{mL}$ and $46.4 \mathrm{ng} / \mathrm{mL}$ in patients with distant recurrence. The postoperative serum calcitonin level was positive $(>5 \mathrm{pg} / \mathrm{mL})$ in all patients with local or distant recurrence (25/25 and 20/20, respectively), whereas postoperative serum CEA level was positive ( $>5 \mathrm{ng} / \mathrm{mL})$ in $56.0 \%(14 / 25)$ of patients

Table 4. Comparison of the clinicopathologic characteristics between preoperative serum CEA-positive $(>5 \mathrm{ng} / \mathrm{mL})$ and CEA-negative patients

\begin{tabular}{|c|c|c|c|}
\hline & $\begin{array}{l}\text { CEA-positive patients } \\
n=51\end{array}$ & $\begin{array}{l}\text { CEA-negative patients } \\
n=43\end{array}$ & p \\
\hline \multicolumn{4}{|l|}{ Serum CEA } \\
\hline Median (IQR) & $21.5(11.6-47.3)$ & $2.3(1.2-3.6)$ & $<0.001$ \\
\hline Age, years $($ mean $\pm S D)$ & $53.22 \pm 16.12$ & $49.42 \pm 12.56$ & 0.206 \\
\hline Sex, female (\%) & $31(60.8 \%)$ & $25(58.1 \%)$ & 1.000 \\
\hline Multifocality & $12(23.5 \%)$ & $7(16.3 \%)$ & 0.470 \\
\hline Size, cm (mean $\pm S D)$ & $2.41 \pm 1.48$ & $1.13 \pm 1.14$ & $<0.001$ \\
\hline Gross ETE, present (\%) & $13(25.5 \%)$ & $1(2.3 \%)$ & 0.004 \\
\hline N stage & & & $<0.001$ \\
\hline 0 & 15 & 30 & \\
\hline $1 \mathrm{a}$ & 7 & 9 & \\
\hline $1 b$ & 29 & 4 & \\
\hline \multicolumn{4}{|l|}{ Metastatic LN, number } \\
\hline Median (IQR) & $7(0-11)$ & $0(0-1)$ & 0.003 \\
\hline Clinical outcome, number (\%) & & & 0.026 \\
\hline No evidence of structural disease & $42(82.4)$ & $41(95.3)$ & \\
\hline Structural recurrence & $8(15.7)$ & $0(0)$ & \\
\hline Death & $1(1.9)$ & $2(4.7)$ & \\
\hline
\end{tabular}

CEA: carcinoembryonic antigen, ETE: extrathyroidal extension, IQR: interquartile range, LN: Iymph node, SD: standard deviation

Table 5. Sensitivity of serum calcitonin and CEA levels at detection of recurrence

\begin{tabular}{|c|c|c|c|c|c|c|}
\hline \multirow{2}{*}{ Total number } & & \multicolumn{2}{|c|}{ Number of positive patients } & \multicolumn{2}{|c|}{ Sensitivity (\%) } & \multirow{2}{*}{$\begin{array}{c}\text { Increase in sensitivity } \\
\text { by adding CEA }\end{array}$} \\
\hline & & Calcitonin & CEA & Calcitonin & CEA & \\
\hline Local recurrence & 25 & 25 & 14 & 100 & 56.0 & $0 \%$ \\
\hline Distant recurrence & 20 & 20 & 16 & 100 & 80.0 & $0 \%$ \\
\hline
\end{tabular}

CEA: carcinoembryonic antigen 
with local recurrence and in $80.0 \%(16 / 20)$ of patients with distant recurrence (Table 5). Even for the four patients who died due to progression of the disease, the serum CEA level was within the normal range (Table 6 and Fig. 3).

\section{Discussion}

In this study, serum CEA had lower sensitivity than serum calcitonin not only at the initial diagnosis (94.7\% vs. 54.3\%), but also for detecting local recurrence (100\% vs. $56.0 \%)$ and for confirming distant metastasis (100\% vs. $80.0 \%)$. Serum calcitonin and CEA levels can be used as indicators, and guidelines recommend assessing both biomarkers when family members are screened for risk and for follow-up after thyroidectomy for MTC. ${ }^{10)}$ During patient surveillance and follow-up, it is important to assess the presence
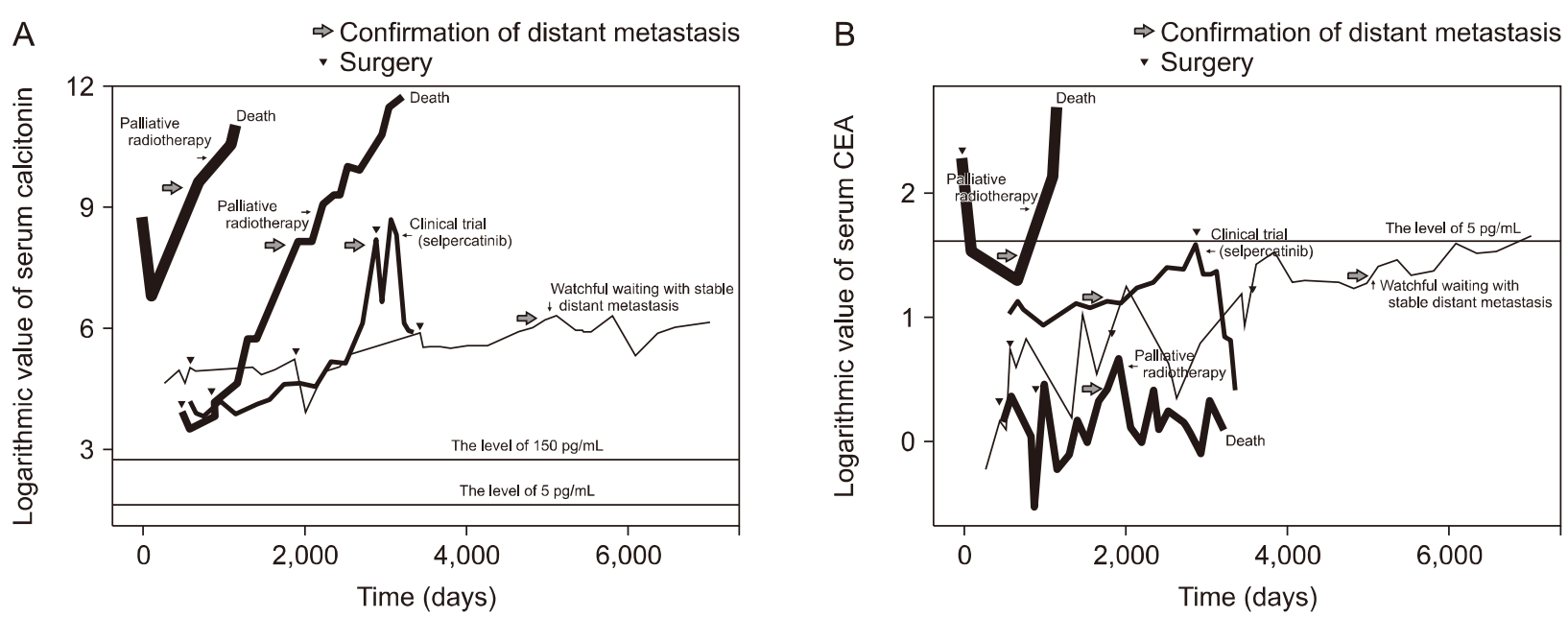

Fig. 3. Serial changes in serum calcitonin (A) and CEA (B) levels of CEA-negative $(<5 \mathrm{ng} / \mathrm{mL})$ patients.

Table 6. Clinical outcomes of CEA-negative patients at detection of recurrence

\begin{tabular}{|c|c|c|c|c|c|c|c|c|c|}
\hline Age & Sex & T stage & $\begin{array}{l}\text { Size } \\
(\mathrm{cm})\end{array}$ & $\begin{array}{c}m L N \\
\text { (Number) }\end{array}$ & $\begin{array}{c}\mathrm{N} \\
\text { stage }\end{array}$ & $\begin{array}{c}\text { Metastasis } \\
\text { (site) }\end{array}$ & $\begin{array}{c}\text { Calcitonin } \\
(\mathrm{pg} / \mathrm{mL})\end{array}$ & $\begin{array}{c}\text { CEA } \\
(\mathrm{ng} / \mathrm{mL})\end{array}$ & $\begin{array}{l}\text { Clinical } \\
\text { outcome }\end{array}$ \\
\hline \multicolumn{10}{|c|}{ Patients with local recurrence } \\
\hline 30 & $\mathrm{~F}$ & $3 a$ & 4.0 & 10 & $1 b$ & LN & 185 & 1.3 & Recur $^{a}$ \\
\hline 50 & $M$ & $1 \mathrm{a}$ & 1.6 & 2 & $1 a$ & LN & 399 & 2.4 & Death \\
\hline 58 & M & $1 b$ & 1.4 & 3 & $1 a$ & LN & 312 & 0.5 & Recur \\
\hline 49 & $\mathrm{~F}$ & $3 b$ & 1.5 & 11 & $1 b$ & LN & 162 & 0.5 & Recur \\
\hline 52 & M & $1 b$ & 0.9 & 2 & $1 b$ & LN & 66 & 2.8 & Recur ${ }^{b}$ \\
\hline 47 & $\mathrm{~F}$ & 2 & 2.6 & 3 & $1 a$ & LN & 51 & 1.2 & Death $^{c}$ \\
\hline 51 & M & $1 \mathrm{a}$ & 1.0 & 3 & $1 a$ & LN & 131 & 2.0 & Recur \\
\hline 21 & M & $1 \mathrm{a}$ & 0.6 & 7 & $1 a$ & LN & 159 & 3.0 & Recur \\
\hline 37 & $\mathrm{~F}$ & $1 b$ & 1.5 & 24 & $1 b$ & LN & 549 & 0.7 & Recur \\
\hline 57 & $\mathrm{~F}$ & $1 \mathrm{a}$ & 1.2 & 1 & $1 a$ & LN & 78 & 2.4 & Recur \\
\hline 42 & $\mathrm{~F}$ & $3 a$ & 5.6 & 14 & $1 b$ & LN & 4542 & 4.2 & Recur \\
\hline \multicolumn{10}{|c|}{ Patients with distant recurrence } \\
\hline 30 & $\mathrm{~F}$ & $3 a$ & 4.0 & 10 & $1 b$ & Lung & 401 & 3.4 & Recur ${ }^{a}$ \\
\hline 52 & $M$ & $1 \mathrm{a}$ & 0.9 & 2 & $1 b$ & Lung & 770 & 3.8 & Recur ${ }^{b}$ \\
\hline 47 & $\mathrm{~F}$ & 2 & 2.6 & 3 & $1 a$ & Bone & 3320 & 1.1 & Death $^{c}$ \\
\hline 72 & $M$ & $3 a$ & 6.5 & 46 & $1 b$ & Liver & 14826 & 3.6 & Death \\
\hline
\end{tabular}

CEA: carcinoembryonic antigen, $L N$ : lymph node, $m L N$ : metastatic lymph node

${ }^{a, b, c}$ Results observed for the clinical course of the same patient are indicated by the same letter. 
of cancer to diagnose and treat patients early. Although the cost of CEA testing varies by country and healthcare system, the low sensitivity of serum CEA testing undermines the clinical significance of serum CEA level in terms of cost-effectiveness.

Preoperative serum calcitonin level was positively correlated with extent of disease and was related to postoperative biochemical normalization and prognosis. ${ }^{11,12)}$ Preoperative serum CEA is also well correlated with anatomical stage, and the level increases characteristically in advanced disease. ${ }^{13,14)}$ In this study, serum calcitonin level was significantly correlated with serum CEA level ( $R=0.78, p<0.001$, Fig. 1), and both were significantly correlated with the extent of disease (Fig. 2). In addition, the sensitivity of biomarkers was higher in advanced disease because the level of biomarkers was associated with disease burden (Table 2).

Serum calcitonin has been emphasized as a diagnostic marker for MTC because of the low accuracy of cytologic diagnosis, ${ }^{15)}$ although routine screening of serum calcitonin in thyroid nodules is controversial when the actual prevalence of MTC is considered. ${ }^{16)}$ For calcitonin, the normal range varies depending on age and sex. ${ }^{17)}$ In this study, the preoperative calcitonin cut-off level was set to $12 \mathrm{pg} / \mathrm{mL}$ based on the results of our previous study. ${ }^{9}$ In this study, five of 94 patients (5.32\%) had calcitonin-negative MTC. Several studies have reported MTC patients with low serum calcitonin level. In their multicenter study, Frank-Raue et al. ${ }^{18)}$ analyzed 839 patients and reported that the prevalence of calcitonin-negative MTCs was $0.83 \%$ and suggested that the patients' prognoses were heterogeneous. The relatively high prevalence compared to previous studies is likely due to the involvement of many microcarcinomas, which were not included in other studies. The primary tumor size of all the calcitonin-negative cases in this study was less than $1 \mathrm{~cm}$ and ranged from 0.3 to $0.7 \mathrm{~cm}$. All but one of the patients were diagnosed as stage I, and postoperative remission was maintained through the end of this study (Table 3).

Serum CEA is used for various types of cancers as an inexpensive and non-invasive blood-borne biomarker. ${ }^{19)}$ However, serum CEA level is increased in various benign diseases, in smokers, and in cancer patients, ${ }^{20)}$ and it is often within the normal range even when the patient is diagnosed with cancer. ${ }^{211}$ Therefore, serum CEA measurement has low sensitivity and specificity and relatively low diagnostic value. It has been reported that serum CEA value is not useful in early diagnosis of MTC, and the positive rate of CEA in MTC was reported as $62 \%$ in a previous study. ${ }^{22)}$ In consideration of the high false-positive rate of the CEA test, $5 \mathrm{ng} / \mathrm{mL}$, which is the standard cut-off for smokers, was selected as the cut-off level in this study. The positive rate of CEA in MTC was confirmed to be $54.3 \%$ in this study, and the positive rate increased according to anatomical stage ( $p$ for trend $<0.001$; Table 2). Positivity of CEA was associated with known poor prognostic factors, such as primary tumor size, gross extrathyroidal extension, and N1b (Table 4). This explains the high positive rate in the patients with advanced MTC.

Some reports have suggested that measuring serum CEA is useful for follow-up in patients with MTC. In 1978, Wells et al. ${ }^{22)}$ reported the value of serum CEA level for evaluating disease progression in MTC patients. In 1984, Mendelsohn et al. ${ }^{23)}$ reported that some patients with aggressive disease had increasing serum CEA level despite stable or declining serum calcitonin level. In 2017, Zhou et al. ${ }^{24)}$ suggested that CEA is useful because elevated level was observed in a group of calcitonin-negative patients. In the present study cohort, however, serum CEA increased with serum calcitonin, and some cases showed increased serum calcitonin without increased serum CEA (Table 6 and Fig. 3); the inverse case was not observed. Therefore, we suggest that measurement of serum CEA level plays a limited role in diagnosis and follow-up of MTC and cannot be substituted for serum calcitonin testing.

From a biological point of view, calcitonin and CEA have different pathways for production and excretion. ${ }^{25)}$ Calcitonin is stained in the secretory granules of the parafollicular C cells that constitute MTC, and the level clearly increases in response to stimulation by compounds such as calcium or pentagastrin. CEA is expressed on the cell membrane, and the degree of ex- 
pression on the cell membrane increases with differentiation of cancer. ${ }^{26,27)}$ Although CEA level is associated with aggressive features in many other carcinomas, metastasis can occur without CEA elevation. ${ }^{28,29)}$ This was confirmed in our study cohort of patients with MTC. The proportion of patients with positive serum CEA level at detection of distant metastasis on postoperative follow-up was $80 \%$ (Table 4), but serum CEA was not increased in all of those patients (Table 6 and Fig. 3). Serum CEA level is thought to be affected not only by CEA production by malignant cells, but also by the degree of excretion of CEA into systemic circulation, which might be associated with the tumor microenvironment. ${ }^{30)}$

The primary limitation of this study was the retrospective design and that subjects were enrolled from a single institution. In addition, a fixed cut-off $(5 \mathrm{ng} / \mathrm{mL})$ of serum CEA was used for statistical analysis. This study was based on clinical experience with a relatively large number of patients with MTC, but other series might show different results from this study. The results should be considered and applied within these contexts.

The CEA value is associated with anatomical stage as a biomarker for MTC and could be used to predict poor prognosis. However, serum CEA testing plays a limited role in diagnosis and follow-up of MTC because it can show normal values even in advanced disease.

\section{Conflicts of Interest}

No potential conflict of interest relevant to this article was reported.

\section{Orcid}

Jinyoung Kim: https://orcid.org/0000-0003-4581-9493

Hyunju Park: https://orcid.org/0000-0002-6010-5539

Min Sun Choi: https://orcid.org/0000-0002-7327-2838

Jun Park: https://orcid.org/0000-0002-7873-1458

Hye Won Jang: https://orcid.org/0000-0002-3053-7138

Tae Hyuk Kim: https://orcid.org/0000-0002-7975-2437

Sun Wook Kim: https://orcid.org/0000-0002-6858-3439
Jae Hoon Chung: https://orcid.org/0000-0002-9563-5046

\section{References}

1) Hazard JB, Hawk WA, Crile G Jr. Medullary (solid) carcinoma of the thyroid; a clinicopathologic entity. J Clin Endocrinol Metab 1959;19(1):152-61.

2) Kebebew E, Ituarte PH, Siperstein AE, Duh QY, Clark OH. Medullary thyroid carcinoma: clinical characteristics, treatment, prognostic factors, and a comparison of staging systems. Cancer 2000;88(5):1139-48.

3) Williams ED. Histogenesis of medullary carcinoma of the thyroid. J Clin Pathol 1966;19(2):114-8.

4) de Groot JW, Kema IP, Breukelman H, van der Veer E, Wiggers T, Plukker JT, et al. Biochemical markers in the follow-up of medullary thyroid cancer. Thyroid 2006;16(11): 1163-70.

5) Saad MF, Fritsche HA Jr, Samaan NA. Diagnostic and prognostic values of carcinoembryonic antigen in medullary carcinoma of the thyroid. J Clin Endocrinol Metab 1984;58(5): 889-94.

6) Wells SA Jr, Asa SL, Dralle H, Elisei R, Evans DB, Gagel $\mathrm{RF}$, et al. Revised American Thyroid Association guidelines for the management of medullary thyroid carcinoma. Thyroid 2015;25(6):567-610.

7) Barbet J, Campion L, Kraeber-Bodéré F, Chatal JF, GTE Study Group. Prognostic impact of serum calcitonin and carcinoembryonic antigen doubling-times in patients with medullary thyroid carcinoma. J Clin Endocrinol Metab 2005;90(11): 6077-84.

8) Laure Giraudet A, Al Ghulzan A, Auperin A, Leboulleux S, Chehboun A, Troalen F, et al. Progression of medullary thyroid carcinoma: assessment with calcitonin and carcinoembryonic antigen doubling times. Eur J Endocrinol 2008;158(2):239-46.

9) Hahm JR, Lee MS, Min YK, Lee MK, Kim KW, Nam SJ, et al. Routine measurement of serum calcitonin is useful for early detection of medullary thyroid carcinoma in patients with nodular thyroid diseases. Thyroid 2001;11(1):73-80.

10) Fagin JA, Wells SA Jr. Biologic and clinical perspectives on thyroid cancer. N Engl J Med 2016;375(11):1054-67.

11) Cohen R, Campos JM, Salaun C, Heshmati HM, Kraimps JL, Proye C, et al. Preoperative calcitonin levels are predictive of tumor size and postoperative calcitonin normalization in medullary thyroid carcinoma. Groupe d'Etudes des Tumeurs a Calcitonine (GETC). J Clin Endocrinol Metab 2000;85(2):919-22.

12) Opsahl EM, Akslen LA, Schlichting E, Aas T, Brauckhoff K, Hagen AI, et al. The role of calcitonin in predicting the extent of surgery in medullary thyroid carcinoma: a nationwide population-based study in Norway. Eur Thyroid J 2019;8(3): 159-66.

13) Machens A, Ukkat J, Hauptmann S, Dralle H. Abnormal carcinoembryonic antigen levels and medullary thyroid cancer progression: a multivariate analysis. Arch Surg 2007;142(3):28993; discussion 94.

14) Turkdogan S, Forest VI, Hier MP, Tamilia M, Florea A, 
Payne RJ. Carcinoembryonic antigen levels correlated with advanced disease in medullary thyroid cancer. J Otolaryngol Head Neck Surg 2018;47(1):55.

15) Elisei R, Bottici V, Luchetti F, Di Coscio G, Romei C, Grasso $\mathrm{L}$, et al. Impact of routine measurement of serum calcitonin on the diagnosis and outcome of medullary thyroid cancer: experience in 10,864 patients with nodular thyroid disorders. J Clin Endocrinol Metab 2004;89(1):163-8.

16) Daniels GH. Screening for medullary thyroid carcinoma with serum calcitonin measurements in patients with thyroid nodules in the United States and Canada. Thyroid 2011;21(11):1199207.

17) Deftos LJ, Weisman MH, Williams GW, Karpf DB, Frumar $\mathrm{AM}$, Davidson BJ, et al. Influence of age and sex on plasma calcitonin in human beings. N Engl J Med 1980;302(24):1351-3.

18) Frank-Raue $K$, Machens $A$, Leidig-Bruckner G, Rondot $S$, Haag C, Schulze E, et al. Prevalence and clinical spectrum of nonsecretory medullary thyroid carcinoma in a series of 839 patients with sporadic medullary thyroid carcinoma. Thyroid 2013;23(3):294-300.

19) Ballesta AM, Molina R, Filella X, Jo J, Gimenez N. Carcinoembryonic antigen in staging and follow-up of patients with solid tumors. Tumour Biol 1995;16(1):32-41.

20) Chung S. False-positive elevations in carcinoembryonic antigen levels at a Health Screening Center. Lab Med Online 2019;9(3): 146-52.

21) Hara M, Kanemitsu $Y$, Hirai T, Komori $K$, Kato T. Negative serum carcinoembryonic antigen has insufficient accuracy for excluding recurrence from patients with Dukes $C$ colorectal cancer: analysis with likelihood ratio and posttest probability in a follow-up study. Dis Colon Rectum 2008;51(11):1675-80.

22) Wells SA Jr, Haagensen DE Jr, Linehan WM, Farrell RE, Dilley WG. The detection of elevated plasma levels of carcino- embryonic antigen in patients with suspected or established medullary thyroid carcinoma. Cancer 1978;42(3 Suppl):1498-503.

23) Mendelsohn G, Wells SA Jr, Baylin SB. Relationship of tissue carcinoembryonic antigen and calcitonin to tumor virulence in medullary thyroid carcinoma. An immunohistochemical study in early, localized, and virulent disseminated stages of disease. Cancer 1984;54(4):657-62.

24) Zhou Q, Yue S, Cheng Y, Jin J, Xu H. Clinical and pathological analysis of 19 cases of medullary thyroid carcinoma without an increase in calcitonin. Exp Toxicol Pathol 2017; 69(8):575-9.

25) Osamura RY, Yasuda $O$, Kawakami $T$, Itoh $Y$, Inada $K$, Kakudo K. Immunoelectron microscopic demonstration of regulated pathway for calcitonin and constitutive pathway for carcinoembryonic antigen in the same cells of human medullary carcinomas of thyroid glands. Mod Pathol 1997;10(1):7-11.

26) Wang J, Chu Y, Li J, Wang T, Sun L, Wang P, et al. The clinical value of carcinoembryonic antigen for tumor metastasis assessment in lung cancer. PeerJ 2019;7:e7433.

27) Duffy MJ. Carcinoembryonic antigen as a marker for colorectal cancer: is it clinically useful? Clin Chem 2001;47(4):624-30.

28) Sørensen CG, Karlsson WK, Pommergaard HC, Burcharth $\mathrm{J}$, Rosenberg J. The diagnostic accuracy of carcinoembryonic antigen to detect colorectal cancer recurrence - a systematic review. Int J Surg 2016;25:134-44.

29) Guadagni F, Ferroni P, Carlini S, Mariotti S, Spila A, Aloe $\mathrm{S}$, et al. A re-evaluation of carcinoembryonic antigen (CEA) as a serum marker for breast cancer: a prospective longitudinal study. Clin Cancer Res 2001;7(8):2357-62.

30) Saito G, Sadahiro S, Okada K, Tanaka A, Suzuki T, Kamijo A. Relation between carcinoembryonic antigen levels in colon cancer tissue and serum carcinoembryonic antigen levels at initial surgery and recurrence. Oncology 2016;91(2):85-9. 